\title{
Switching to blended learning: The impact on students' academic performance
}

\author{
Zhigang $\mathrm{Li}^{1}$, Ming-Hsiu Tsai ${ }^{2}$, Jinyuan $\mathrm{Tao}^{3}$, Chris Lorentz ${ }^{3}$ \\ 1. Southern Polytechnic State University, Marietta, Georgia, USA. 2. National Taipei University of Technology, Taipei, \\ Taiwan. 3. Adventist University of Health Sciences, Orlando, Florida, USA.
}

Correspondence: Jinyuan Tao. Address: Adventist University of Health Sciences, Orlando, Florida, USA. Email: david.tao@adu.edu

Received: October 11, 2013

Accepted: December 2, $2013 \quad$ Online Published: January 16, 2014

DOI : $10.5430 /$ jnep.v4n3p245

URL: http://dx.doi.org/10.5430/jnep.v4n3p245

\begin{abstract}
As more and more undergraduate nursing programs (UNP) adopt the blended learning model, which combines traditional face-to-face learning and e-learning, how it impacts on students' academic performance comes into educators' mind. The purpose of this study was to investigate whether the blended learning model adopted by a UNP could yield the same, if not better academic achievement as compared with the traditional classroom learning. Students enrolled in two undergraduate nursing courses in fall 2008 and spring 2009 semesters were taken as a convenient sample. Students' academic achievements were compared before and after the two undergraduate nursing courses adopted blended learning. Faculty members who taught those courses before and after the adoption were interviewed for insights on students' complains and their corresponding solutions. The statistic results showed that there was no significant difference in terms of academic performance before and after the courses adopted blended learning. Interviews from the faculty members suggested that there was some initial resistance from the students on taking the online content outside of class. Pop quizzes at the beginning of each face-to-face class helped motivate students to complete the online portion at home prior coming to the class.
\end{abstract}

\section{Key words}

Blended learning, Traditional classroom teaching, Nursing education, Face-to-face teaching, E-learning, Student performance

\section{I ntroduction}

The Internet technologies are one of the fastest growing and the most penetrated technologies in the world. According to Internet World Stats ${ }^{[1]}$, the penetration rate of the Internet in North America is as high as 77.4 percent of the population. Given the ubiquity of the Internet and the benefits it provides, it is obvious that educators would want to take advantage of it for educational purposes ${ }^{[2]}$.

There is no doubt about the proliferation of e-learning in recent years. The much-heated media debate is fading out quietly as e-learning is no longer a trend, but a fact. According to Global Industry Analysts (GIA), the e-learning market in the U. S. was $\$ 17.5$ billion in 2007. The global e-learning market is going to reach $\$ 107.3$ billion by $2015^{[3]}$. In a recent market 
analysis, Ambient Insight concludes that the worldwide market for self-pacing e-learning products and services reached $\$ 27.1$ billion in 2009 and the revenues will reach $\$ 49.6$ billion by $2014{ }^{[4]}$.

There are many advantages that e-learning can offer over the traditional face-to-face teaching method. A few examples of the benefits include: 1) enhancing student-to-student and faculty-to-student communication, 2) enabling student-centered teaching approaches, 3) providing 24/7 accessibility to course materials, 4) providing just-in-time methods to assess and evaluate student progress, and 5) students can attend a course at any time, from anywhere ${ }^{[5,6]}$.

Despite its many advantages, there are various challenges facing e-learning as well. High dropout rates and low start rates were reported in different studies ${ }^{[7,8]}$. Resource challenge such as limited network access, problems with technology, and lack of oversight is also a concern ${ }^{[9]}$. To glean the best of both worlds of traditional classroom teaching and e-learning, researchers have suggested a new teaching environment: blended learning. Blended learning combines both face-to-face and e-learning. Since then, more and more institutes have started adopting blended learning in order to provide the best learning environment for the students and also reduce cost ${ }^{[10-12]}$.

Blended learning is commonly defined as the combination of traditional classroom-based approach and e-learning for delivering instruction ${ }^{[11,13-15]}$. In the blended learning environment, students take the advantages of the traditional face-to-face learning environment where they interact with their instructors, as well as enjoying the flexibility that e-learning provides. Research studies suggested that blended learning helps to reduce dropout rates and yields better student performance ${ }^{[16,17]}$. Blended learning also helps teachers to find ways that better engage students by using online tools and resources they are already using or familiar with ${ }^{[18]}$.

\subsection{Undergraduate nursing program}

The undergraduate nursing programs (UNP) in the United States usually follow the brick-and-mortar model that adopts the face-to-face teaching environment. It is mainly due to nursing field's practice-oriented characteristic. More and more UNPs started to adopt blended learning model where e-learning and the traditional classroom teaching co-exist. In the e-learning part, lectures are typically pre-recorded and hosted in the learning management system for students to access 24/7 during the entire semester. At the same time, the traditional face-to-face teaching is still conducted on regular basis to reinforce e-learning.

This study was conducted in a private four-year university, which specializes in health care education in the United States. Directed by the university administration, the undergraduate nursing program gradually migrated to a blended learning model in 2008. By the end of 2009, all nursing courses had converted to the blended learning environment. To help nursing faculties better understand the concept of the blended learning model, the university described its blended learning model into two parts: 1) the traditional face-to-face teaching part, where students meet their instructors, typically once or twice a week. Classroom learning activities include clinical case study analysis, quizzes, exams, instructional games, mannequinbased simulations, videos, exam practice questions, discussions, and question and answers; 2) the e-learning part, where all the teaching content is designed and pre-recorded by professional course developers. Students can access that Flash-based content 24/7 during the entire trimester. At the same time, the majority of homework are distributed and collected within the learning management system electronically. Obviously, this blended learning model is the "flipped classroom" approach where students learn new content online by watching video lectures, usually at home, and what used to be homework is now done in class with teacher offering more personalized guidance and interaction with students, instead of lecturing ${ }^{[19]}$.

For example, Figure 1 shows a typical pre-recorded lecture interface. Using Flash technology, text is designed to pop up on the screen and it is synchronized with the professional voice over. Those pre-recorded lectures allow students to access 24/7 during the entire trimester. While viewing the online lectures, students also have the flexibility to rewind and fast forward. During course orientation, students are reminded to review those pre-recorded lectures beforehand and read related textbook before they attend the traditional face-to-face classes. 


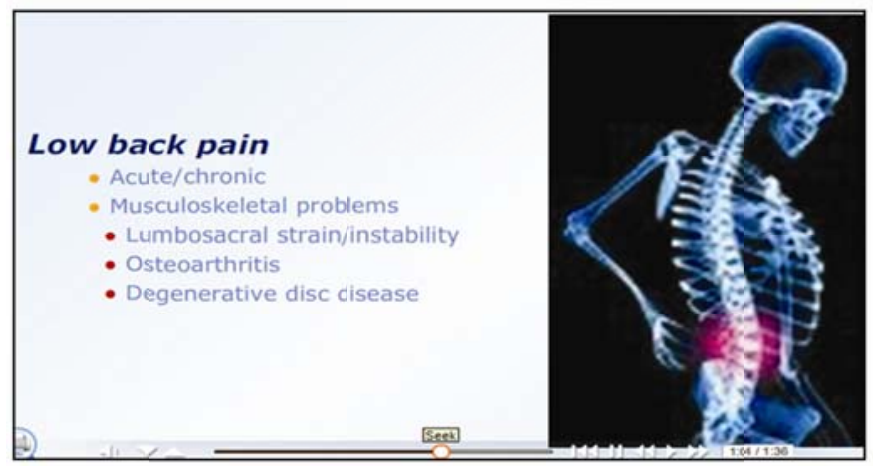

Figure 1. A typical interface of a recorded lecture

\section{Critical thinking preparation}

A patient hospitalized with possible acute pancreatitis has severe abdominal pain $8 / 10$, and complains of nausea.

What should the nurse do first?

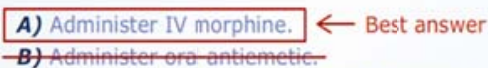

C) Place ode compress on patient's forehead.

D) Give patient-sips of water.

Figure 2. Interface of an embedded learning activity

Instructors design a variety of interactive activities such as drag-and-drop, ordering, matching, and short quizzes periodically throughout the pre-recorded lectures to make it more interactive and engaging. The goal is to reinforce learning (see Figure 2). Students must finish those short activities in order to move on to the next topic.

For the face-to-face teaching and learning part, traditional classes are typically held once a week. Students prepare for the live teaching by going over the pre-recorded lectures online (the e-learning part) and designated textbook readings. Typical face-to-face teaching and learning activities include case studies, tests, quizzes, games, simulations, stories, videos, practice questions, and discussions ${ }^{[20]}$. However, different instructors use different strategies in the traditional face-to-face teaching classroom (see Figure 3).

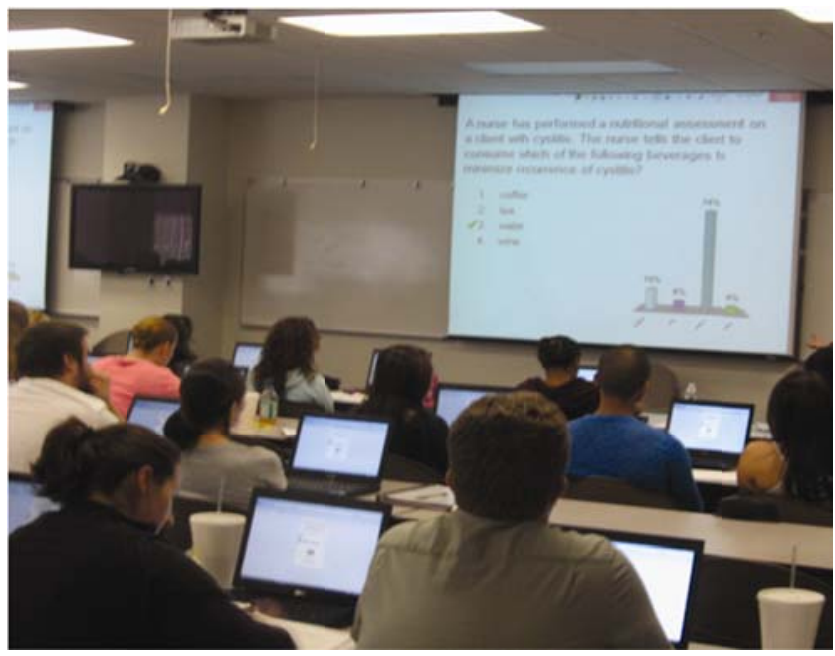

Figure 3. A typical traditional classroom where an instructor is using Clickers ${ }^{\mathrm{TM}}$ technology to engage students 


\subsection{Purpose of study}

The purpose of this preliminary research study was to investigate students' academic performance before and after the adoption of blended learning by an undergraduate nursing program. It examined whether blended learning could yield the same, if not better academic achievement as compared with traditional classroom learning.

\section{Method}

\subsection{Research design}

The present study is a causal comparative research, which is an after-effect natural experiment. Because of the University policy and efforts in promoting blended learning in spring 2009, pre-existing data concerning its effects on student achievements were obtained for the purpose of this research. The independent variable was the instructional delivery method, which includes two levels: traditional face-to-face instruction (fall 2008), and blended learning (spring 2009). The dependent variable was students' academic achievement, which were the final percentage grades for the courses.

\subsection{Participants}

The participants were students from two undergraduate nursing courses NRSG110 and NRSG111 offered in fall 2008 and spring 2009 at a university in southeastern region of the US. Both courses were offered in traditional face-to-face method during fall 2008 semester and both adopted blended learning method during spring 2009 semester. NRSG110 and NRSG111 were taught by two different instructors but each instructor taught the same course for the two terms. Meanwhile, the courses had students of similar backgrounds; 66 students enrolled in NRSG110 traditional face-to-face class in fall 2008, and 69 students in blended learning NRSG110 class in spring 2009. For NRSG111 course, 65 students were enrolled in fall 2008, and 68 students in spring 2009.

In order to understand the instructors' perceptions toward blended learning in nursing, the two instructors who taught NRSG110 and NRSG111 were interviewed and were asked about their perception about the blended learning adoption.

\subsection{Instruments}

NRSG110 "Introduction to Nursing” introduces the student to the profession of nursing, Neuman Systems Model and the nursing process. The course was designed for students to develop critical thinking and communication skills necessary for the professional practice of nursing. NRSG110 is heavy in concrete concepts, history events, and terminologies. NRSG 111 "Foundations of Nursing" focuses on the application of the nursing process in the provision of primary and secondary prevention and strengthening the adult client/patient lines of defense and resistance to environmental stressors. Upon taking the course, students will identify basic stressors affecting the physiological, psychological, sociocultural, developmental and spiritual variables of client/patient system. In addition, students will also be able to provide care within the acute care and community environments. NRSG111is an application-oriented course where students had to apply concepts into real nursing scenarios. However, being different in the nature and focus, both courses provide students a blended learning mode offering pre-recorded lectures of the course contents on the university's learning management system.

For the measurement of students' achievement (dependent variable), the instructors used the exact same tests each term during fall 2008 semester and spring 2009 semester; their percentage grade were obtained for data analysis.

Independent $t$-test was used in SPSS TM to determine if there was any statistically significant difference between students' performance before and after the adoption of blended learning. Qualitative data from instructors were recorded and transcribed for analysis and themes were identified and analyzed to provide a greater depth of understanding that supplements the descriptive statistics findings. 


\section{Results}

\subsection{Quantitative results}

For course NRSG110 (see Table 1), there were 66 students enrolled in the class for the fall 2008 and the average grade was 83.86 (std. = 9.38). 69 students were enrolled in the class for spring 2009 and the average grade was 85.07 (std. = 5.35). Students had a slightly better performance in blended learning environment. A $t$-test performed on the grades showed no significant difference between the fall 2008 class and spring 2009 class, with $t=-.93$ and $p>.05$; that is, the students in the traditional face-to-face teaching model (fall 2008) and the blended learning model (spring 2009) had equivalent academic achievements in course NRSG110.

Table 1. $t$-test result for Course NRSG110

\begin{tabular}{lllll}
\hline Class & N & Mean & SD & t \\
\hline NRSG110 Fall 2008 & 66 & 83.86 & 9.38 & -.93 \\
NRSG110 Spring 2009 & 69 & 85.07 & 5.35 & \\
\hline$* p<.05$ & & & &
\end{tabular}

For course NRSG111 (see Table 2), 65 students were enrolled in fall 2008 and the average grade was 83.65 (std. = 5.44). In spring 2009, 68 students were enrolled and the average grade was 82.95 (std. $=8.08$ ). Students had a slightly poorer performance in blended learning environment. A $t$-test performed on the grades showed no significant difference between the fall 2008 class and spring 2009 class, with $t=.58$ and $p>.05$; that is, the students in the traditional face-to-face teaching model (fall 2008) and the blended learning model (spring 2009) had equivalent academic achievements in course NRSG111.

Table 2. $t$-test result for Course NRSG111

\begin{tabular}{lllll}
\hline Class & N & Mean & SD & t \\
\hline NRSG111 Fall 2008 & 65 & 83.65 & 5.44 & .58 \\
NRSG111 Spring 2009 & 68 & 82.95 & 8.08 & \\
\hline
\end{tabular}

${ }^{*} p<.05$

Overall, in terms of academic performance of both nursing courses, students in blended learning environment perform at the same level as the students in the traditional face-to-face teaching model. However, for NRSG110, the average grades improved slightly after switching to blended learning model; for NRSG111, the average grades went down slightly in blended learning setting. Possible reason could be the fact that NRSG110 was different from NRSG111 in terms of the content. NRSG110 was heavy in concrete concepts, history events, and terminologies that required a lot of mechanical memorization. Blended learning showed its advantage by offering students $24 / 7$ access to the pre-recorded lectures in its e-learning part, thus was able to help students learn by repetition. For NRSG111, the blended learning didn't help improve the grades, possibly because the course was application-oriented where students had to apply concepts into real nursing scenarios. This type of learning wouldn't improve much by simple repetitions; rather, the traditional form of face-to-face teaching that focused on lecturing, discussion, and case studies would show its advantages.

\subsection{Qualitative results}

Interview with nursing faculties who taught the course revealed that many students complained about the switching to blended learning and how they reacted to students’ complaints.

\section{Obstacles in blended learning}

One common theme that evolves from both instructors' interviews was that students were reluctant to review the pre-recorded lectures on their own before the class when blended learning was first introduced. This defeated the purpose 
on the time and effort spent on designing the e-learning portion of the course when students did not spend time studying the online materials. There were two reasons behind students' reluctance to engage in the e-learning part. One was that they were rooted in their belief that learning involves teachers instilling knowledge to students in a traditional face-to-face mode. An instructor mentioned about students' complaint: "Instructors are not teaching the students any more, and the students are teaching themselves (Instructor A)." The other instructor also stated: "I had to emphasize to my students that it is critical to listen to the pre-recorded lectures (e-learning part) before they come to attend the face-to-face classes. I noticed some still wouldn't do it (Instructor B).” The second reason for their reluctance was that they lacked the motivation to view the contents online before the class, especially in their home settings. They could be easily distracted by other things going around, as cited by one of the instructor: "They also complained that they didn't have enough motivation or attention span to listen to the pre-recorded lecture at home or in the library (Instructor A)."

\section{Solutions for blended learning}

As both instructors faced their group of reluctant students, each reacted differently. Instructor A explained to the students that blended learning model was the university's policy in promoting students' learning. Since future courses were to be all offered in blended learning mode; as time went by, students were more willing to accept and embrace blended learning: "Once students realized they didn't have another option, and it is what it is, they seemed to have fewer complaints. The overall grades for later blended learning courses started to pick up (Instructor A).”

Instructor B, on the other hand, took a more aggressive approach in increasing students' effort level on online materials. She implemented a small quiz every time starting the face-to-face classes and found it to be very useful. Quoting instructor B: "If they review the pre-recorded lectures, they will do well on those quizzes. Those small quizzes seemed to work well. More and more students started to pay attention to the pre-recorded lectures."

\section{Discussions and conclusions}

The finding from this study is in line with previous research, which suggested that student performance in the blended

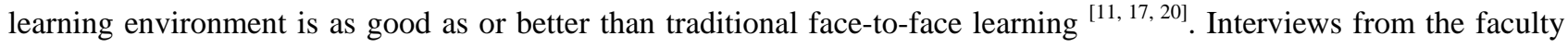
members suggested that there could be initial resistance from students on taking the e-learning content outside of class. Pop quizzes at the beginning of each face-to-face class helped motivate students to complete the e-learning portion at home prior coming to class.

\subsection{Limitations}

This study is limited by its casual comparative research design, which means the results are tentative. Future research may employ experimental research design with random samples, which will yield a more definitive causal-effective relationship from the results. Another limitation of the present study is that it was students' first time to experience blended learning in spring 2009. Without gradual introduction of blended learning, students were neither prepared mentally nor cognitively to adapt to the new learning mode, which affects students' motivation and their learning achievement.

\subsection{I mplications}

As noted from the instructors' interviews on their students' reluctance in reviewing the e-learning content, the following are two recommendations to promote blended learning among students.

As institution begin to implement blended learning, students' learning load and their acceptance to the new learning environment should be taken into consideration. Blended learning courses should be offered at an incremental rate so that the students may take time to experience blended learning and be familiar to the learning requirements gradually.

For the design of the blended learning contents, one thing instructional designers can do to promote students' motivation in previewing the pre-recorded lectures, is to make the pre-recorded lecture more interactive and engaging by adding more 
interactive learning activities such as short quizzes, matching questions, ordering, fill-in-the-blanks, hot-spot, and drag-and-drop into the pre-recorded lectures. For example, every three to four slides, students will have to finish one activity before they move to the new content. This will allow students to interact with the pre-recording, instead of listening to it passively at all times.

\section{References}

[1] Internet World Stats. Internet usage statistics. March 28, 2010. Available from: http://www.internetworldstats.com/stats.htm

[2] Al-Busaidi KA, Al-Shihi H. Instructors' acceptance of learning management systems: A theorectical framework. Communications of the IBIMA. 2010.

[3] PRWeb. Global eLearning market to reach $\$ 107.3$ billion by 2015, according to new report by Global Industry Analysts, Inc. November 6, 2011, Available from: http://www.prweb.com/releases/elearning/corporate_elearning/prweb4531974.htm.

[4] Adkins SS. The worldwide market for self-paced eLearning products and services: 2009-2014 forecast and analysis. Monroe, WA: Ambient Insight, LLC. 2010.

[5] Blackboard Inc. Benefits of online learning. Feburary 26, 2012. Available from: http://www.sacredheart.edu/download/2149_ben_online.pdf

[6] Coleman S. Why do students like online learning? Feburary 26, 2012. Available from: http://www.worldwidelearn.com/education-articles/benefits-of-online-learning.htm

[7] ASTD, The MASIE Center. E-Learning: "If we build it, will they come?". 2001.

[8] O'Conner C, Sceiford E, Wang G, Foucar-Szocki D, Griffin O. Departure, abandonment, and dropout of e-learning: Dilemma and solutions: The MASIE Center. 2003.

[9] Frankola K. Why online learners drop out. Workforce. 2001; 80(10): 53.

[10] Dziuban C, Moskal P. Evaluating distributed learning in metropolitan universities. Metropolitan Universities. 2001; 12(1): 41-49.

[11] Dziuban CD, Moskal PD, Hartman J. Higher education, blended learning, and the generations: Knowledge is power: No more. 2005. In J. Bourne \& J. C. Moore (Eds.), Elements of Quality Online Education: Engaging Communities. Needham, MA: Sloan Center for Online Education.

[12] Pan CC, Sivo S, Gunter G, Cornell R. Students' perceived ease of use of a course management system: an exogenous or endogenous variable? Journal of Educational Computing Research. 2005; 33(3): 285-307. http://dx.doi.org/10.2190/7M4G-R742-W9FT-JX1J

[13] Garrison DR, Kanuka H. Blended learning: Uncovering its transformative potential in higher education. Internet and Higher Education. 2004; 7: 95-105. http://dx.doi.org/10.1016/j.iheduc.2004.02.001

[14] Graham CR. (Eds.), Handbook of blended learning: Global perspectives, local designs. 2004. San Francisco, CA: Pfeiffer Publishing.

[15] Osguthorpe RT., \& Graham CR. Blended learning environments: Definitions and directions. The Quarterly Review of Disntance Education. 2003; 4(3): 227-233.

[16] López-Pérez MV, Pérez-López MC, Rodríguez-Ariza LZ. Blended learning in higher education: Students’ perceptions and their relation to outcomes. Computers \& Education. 2011; 56: 818-826.

[17] Means B, Toyama Y, Murphy R, Bakia M, Jones K. Evaluation of evidence-based practices in online learning: A meta-analysis and review of online learning studies. 2009.

[18] Pape L. Blended Teaching \& Learning. School Administrator. 2010; 67(4): 16-21.

[19] Ronchetti M. Using video lectures to make teaching more interactive. International Journal of Emerging Technologies in Learning, 2010. 5(2).

[20] Taradi SK, Taradi M, Radic K, Pokrajac N. Blending problem-based learning with Web technology positively impacts student learning outcomes in acid-base physiology, Advances in Phsiology Education. 2005; 29: 35-39. PMid:15718381 http://dx.doi.org/10.1152/advan.00026.2004 